\title{
Bonding state of metal-free CAD/CAM onlay restoration after cyclic loading with and without immediate dentin sealing
}

\author{
Noriko ISHII, Toshio MASEKI and Yoichiro NARA \\ Department of Adhesive Dentistry, School of Life Dentistry at Tokyo, The Nippon Dental University, 1-9-20 Fujimi, Chiyoda-ku, Tokyo 102-8159, \\ Japan \\ Corresponding author, Noriko ISHII; E-mail:nn_rr_kk_1014@yahoo.co.jp
}

\begin{abstract}
To examine the bonding state of metal-free CAD/CAM onlay restorations made from two popular resin composite blocks and a typical glass-ceramic block after cyclic loading, with and without immediate dentin sealing (IDS). Standardized mesial-distal-occlusalbuccal (MODB) cavities in 24 extracted human molars were prepared. The intra-cavity dentin surfaces of half of the cavities were immediately sealed with all-in-one adhesive and flowable composite, while those of the other half were not. All cavities were scanned, from which CAD/CAM onlays were fabricated from three types of block and cemented with an adhesive resin cement system. The restored specimens were subjected to cyclic loading and the intra-cavity microtensile bond strength was measured. IDS improves not only the internal bond strength, but also the bond reliability of metal-free CAD/CAM onlay restorations. The resin composite block seems to be more effective than a typical glass-ceramic block for achieving both high bond strength and excellent bond reliability.
\end{abstract}

Keywords: CAD/CAM restoration, Cyclic loading, Immediate dentin sealing, Microtensile bond strength, Weibull analysis

\section{INTRODUCTION}

The trend for metal-free restorative dentistry has fulfilled patients' desire for minimally invasive procedures that offer esthetic value. Direct resin composite restoration is accepted by patients as adequate not only for anterior teeth, but also for posterior teeth, and has a clinical potential that has increased markedly with improvement in resin materials and practical techniques. However, clinical cases involving a large coronal defect that includes the proximal region present challenges for direct resin composite restoration, such as recovery of the proximal contacts and anatomical form, mechanical strength, wear resistance, and gingivo-marginal adaptation as influenced by resin polymerization shrinkage ${ }^{1,2)}$. Metal-free indirect restoration is an effective treatment to resolve these challenges. Preparations for indirect tooth-colored inlays and onlays ${ }^{3)}$ and cavity design principles for indirect restoration, including indirect resin composites and allceramic restorations $\mathrm{s}^{4}$, have been discussed elsewhere.

Conventional indirect restoration involves a series of complicated procedural steps, which include impression-taking, occlusal registration, preparation of a plaster-working model, formation of wax or restorative materials, investing, lost-wax casting, baking, hardening, curing, and additional sintering or curing. Recently, dental computer-aided design/manufacturing (CAD/CAM) systems with vastly simplified procedures for indirect restoration have gained rapid improvements and worldwide usage. In addition, it has been reported that there is no statistical difference in the internal fit between conventional impression restoratives and $\mathrm{CAD} /$ CAM restoratives ${ }^{5}$.

Strong patient demand has driven the development of clinically suitable, metal-free dental materials with various optical and physical properties adapted to $\mathrm{CAD} / \mathrm{CAM}$ technology. Fasbinder ${ }^{6)}$ has recently categorized fabricating blocks for chairside CAD/CAM restorations into various groups: feldspathic esthetic ceramic, leucite-reinforced esthetic ceramic, lithium disilicate high-strength ceramic, nanoceramic and resin composite. On the other hand, Ruse, Sadoun ${ }^{7}$, Zhi and Bortolotto $^{8}$ specified the materials for esthetic CAD/ CAM-processed indirect restorations into two main types, viz., glass-ceramics/ceramics and resin composites. Resin composite block materials may offer significant advantages that are related to their manufacturability, machinability, and reparability ${ }^{7}$, while most of the metal-free materials require firm bonding to the teeth because of their brittleness ${ }^{9}$. Several factors that affect the bonding of metal-free CAD/CAM restorations have been investigated: various ceramic surface treatments on the shear-bond strengths of resin-luting agents to ceramic material discs ${ }^{10}$; curing mode, and surface pretreatment of the CAD/CAM composite block-surface on the microtensile bond strength ( $\mu$-TBS) to dentin ${ }^{11)}$; and different adhesive strategies on the $\mu$-TBS of CAD/ CAM blocks to dentin ${ }^{10,12)}$. The IDS has been extensively examined and the technique helps to ensure robust bond strength $^{13,14)}$, fewer gap formations ${ }^{15)}$, minimal bacterial leakage, and sensitivity limited to the post-operative period $^{16)}$. It was also found that the cyclic loading fatigue significantly decreased the fracture loads of composite resin and all-ceramic crowns, while adhesive cementation significantly expanded the fracture loads ${ }^{17}$. However, no studies to date have examined the intra-cavity bond strength of metal-free CAD/CAM restoration with and without IDS after cyclic loading.

The purpose of this study was to examine the bonding state of metal-free $\mathrm{CAD} / \mathrm{CAM}$ onlay restorations after cyclic loading, simulating the intra-oral 
environment, with and without IDS, by measurement of the $\mu$-TBS, investigation of the bond reliability and observation of the failure mode. The null hypothesis of this study was that IDS and the type of fabricating block would not affect the intra-cavity bond strength and the bond reliability of the $\mathrm{CAD} / \mathrm{CAM}$ onlay restorations after cyclic loading.

\section{MATERIALS AND METHODS}

Experimental materials

Table 1 presents the composition, lot number, and manufacturer of materials used in this study. For the $\mathrm{CAD} / \mathrm{CAM}$ onlays, two popular resin composite blocks were selected: Lava Ultimate (L; 3M ESPE, St Paul, MN, USA), a hyper-cured nano-filler loaded resin composite

Table 1 Materials used

\begin{tabular}{|c|c|c|c|}
\hline $\begin{array}{l}\text { CAD/CAM Restorative } \\
\text { Block Materials }\end{array}$ & Composition & Lot no. & Manufacturer \\
\hline $\begin{array}{l}\text { Lava Ultimate } \\
\text { (Shade: A2-LT) (L) }\end{array}$ & $\begin{array}{l}\text { Silica nanomers }(20 \mathrm{~nm}) \text {, zirconia nanomers }(4-11 \mathrm{~nm}) \text {, } \\
\text { nanocluster particles derived from the nanomers }(0.6-10 \mu \mathrm{m}) \text {, } \\
\text { silane coupling agent, resin matrix }\end{array}$ & N641534 & 3M ESPE \\
\hline $\begin{array}{l}\text { VITA ENAMIC } \\
(\text { Shade: } 2 \mathrm{M} 2-\mathrm{T})(\mathrm{E})\end{array}$ & $\begin{array}{l}\text { Silicon dioxide, aluminum oxide, sodium oxide, potassium oxide, } \\
\text { boron trioxide, zirconia and calcium oxide, UDMA, TEGDMA }\end{array}$ & 40500 & VITA \\
\hline $\begin{array}{l}\text { VITABLOCS Mark II } \\
\text { (Shade: A2C) (V) }\end{array}$ & $\begin{array}{l}\text { Silicon dioxide, aluminum oxide, sodium oxide, potassium oxide, } \\
\text { calcium oxide, titanium dioxide }\end{array}$ & 48940 & VITA \\
\hline \multicolumn{4}{|l|}{ CAD/CAM System } \\
\hline $\begin{array}{l}\text { CEREC AC Omnicam } \\
(\mathrm{sw} 4.3)\end{array}$ & - & 6371830 & \multirow{2}{*}{$\begin{array}{l}\text { SIRONA } \\
\text { Dental } \\
\text { Systems }\end{array}$} \\
\hline CEREC MCXL & - & 6150838 & \\
\hline
\end{tabular}

Immediate Dentin Sealing Materials

Scotchbond Universal

Adhesive

Filtek Supreme Ultra

Flowable Restorative
MDP, Dimethacrylate resins, HEMA, Methacrylate-modified-

Polyalkenoic acid copolymer, Filler, Ethanol, Water, Photo initiators, Silane

$593015 \quad 3 \mathrm{M}$ ESPE

Bis-GMA, Bis-PMA, UDMA, TEGDMA

Non-agglomerated/non-aggregated $75 \mathrm{~nm}$ silica nanofiller; nonagglomerated/non-aggregated 15-20 nm zirconia nanofiller and loosely bound agglomerated zirconia/silica nanocluster, consisting of agglomerates of 5-20 nm primary zirconia/silica particles
N711843 3M ESPE 
block, and VITA ENAMIC (E; VITA Zahnfabrik, Bad Zäckingen, Germany), a resin composite block obtained by infiltration of a pre-sintered ceramic network with a monomer mixture. A typical feldspathic ceramic block, VITABLOCS Mark II (V; VITA Zahnfabrik), commonly applied to CAD/CAM restorations globally with a very high success rate ${ }^{18-20)}$, was chosen as the control in this study. L is composed of both nanomer and nanocluster fillers, with an $80 \%$ total filler content by weight, and is significantly harder and much more wear-resistant than resin alone ${ }^{21}$. $\mathrm{E}$ is comprised of a structure-sintered ceramic matrix, the pores of which are filled with a polymer material; the mass percentage of the inorganic portion is $86 \%{ }^{22)}$. $\mathrm{V}$ is composed of natural feldspar materials, such as potassium feldspar and albite, and it has advantages over other ceramic materials in terms of high purity and a large temperature range during melting ${ }^{23)}$. Both $\mathrm{L}$ and $\mathrm{E}$ blocks were categorized as the resin composite type and $\mathrm{V}$ was classified as the glass ceramic type ${ }^{7,8}$. Well-known chair-side CAD/ CAM systems, CEREC AC Omnicam (SW v. 4.3, SIRONA Dental Systems, Bensheim, Germany) and CEREC MCXL (SIRONA Dental Systems), were used to design and fabricate all onlay restoratives. An allin-one adhesive system was used for IDS: Scotchbond Universal Adhesive (3M ESPE, Seefeld, Germany) was used as a pretreatment for the tooth surface and a lowviscosity restorative composite, and Filtek Supreme Ultra Flowable Restorative (3M ESPE) was used as a sealing material for the surface of dentin. A phosphoric acid etching agent, Scotchbond Universal Etchant (3M ESPE), was applied for $15 \mathrm{~s}$ as a pretreatment for the inner surface of $\mathrm{E}$ and $\mathrm{V}$ restoratives, and as a cleaner for the intra-cavity surface. Thereafter, the etchant was rinsed thoroughly with water, and lightly air dried or blotted dry, leaving a slightly moist surface. Scotchbond Universal Adhesive, the same all-in-one adhesive system used for IDS, was applied and scrubbed for $20 \mathrm{~s}$ as a pretreatment of the inner surface for $\mathrm{L}$ restorative (which should not be cleaned with Scotchbond Universal Etchant), and also to the exposed dentin surface of the intra-cavity wall without resin sealing. After the 20 -s treatment, a gentle stream of air was blown over the liquid for about $5 \mathrm{~s}$, until it no longer moved, and the solvent had evaporated completely. For maximum adhesion, a light irradiation for $10 \mathrm{~s}$ was applied only to the intra-cavity wall. A dual-cure adhesive resin cement, RelyX Ultimate (3M ESPE) was used for luting, regardless of the $\mathrm{CAD} / \mathrm{CAM}$ block type and sealing mode used. Direct-light irradiation was used to cure the Scotchbond Universal Adhesive and Filtek Supreme Ultra Flowable Restorative, and trans-restorative light irradiation to polymerize the RelyX Ultimate below the restorative; a halogen light unit (Optilux 501, SDS Kerr, Orange, CA, USA) with an output of $700 \mathrm{~mW} / \mathrm{cm}^{2}$ was used. Before and after each irradiation, the light intensity was measured and checked with a radiometer (Demetron L.E.D. Radiometer, Kerr).

\section{Tooth selection and restorative procedures}

This study was approved by the Ethics Committee of the Nippon Dental University School of Life Dentistry at Tokyo (approval number NDU-T2012-26). This study utilized 24 caries-free extracted human mandibular first molars stored in $0.1 \%$ thymol solution at $24^{\circ} \mathrm{C}$, and which were used within 1 year after extraction. A schematic flow chart of the experimental procedure is shown in Fig. 1. Each extracted human mandibular molar was embedded in a standardized resin mold by establishing a plane settled with the three apices of the mesiobuccal cusp, distobuccal cusp, and mesiolingual cusp, parallel to the base plane of the mold with an acrylic resin (Adfa, Shofu, Kyoto, Japan) [Fig. 1-(a)]. The nonprepared original crown form of each embedded molar was then scanned using a CEREC AC Omnicam and the scanned data were utilized to reproduce the crown form of each fabricated restorative [Fig. 1-(b)]. Prior to cavity preparation, all tooth specimens were divided into two groups: with IDS (S+, 12 specimens each) and without IDS (S-, 12 specimens each). Standardized mesialdistal-occlusal-buccal (MODB) cavities for both the S+ and S- groups were prepared with a straight cylinder flat-end diamond bur (FG103, ISO \#: 223090 022, mean grit size: $100 \mu \mathrm{m}$; Shofu, Kyoto, Japan) or a straight cylinder round-end diamond bur (FG107RD, ISO \#: 198 090 023, mean grit size; $100 \mu \mathrm{m}$, Shofu) mounted in a custom-made cavity duplicator (Tokyo Giken, Tokyo, Japan), respectively.

First, the pulpal wall was prepared at a depth of $2.0 \mathrm{~mm}$ from the deepest part of the central fossa. The lingual wall was set at a distance of $2.0 \mathrm{~mm}$ from the position of the central fossa. The shoulder preparation (axial wall height: $2.0 \mathrm{~mm}$; gingival wall width: 1.0 $\mathrm{mm}$ ) was performed from the mesio-proximal area to the disto-proximal area. The pulpal-axial line angle of the step-shaped cavities was slightly truncated to complete the standardized MODB protocol [Fig. 1-(c)]. The exposed dentin surface of $\mathrm{S}+$ group cavities was pretreated with Scotchbond Universal Adhesive. Soon thereafter, for IDS, Filtek Supreme Ultra Flowable Restorative (approximately $0.35 \mathrm{~g}$ ) was applied to the dentin surface; it was spread with a small brush to maintain a uniform thickness, and then light-cured. The surface of the sealed resin was thoroughly swabbed with $70 \%$ disinfection ethanol to remove the unpolymerized superficial layer [Fig. 1-(d)].

All cavity specimens were scanned using the CEREC AC Omnicam in accordance with the manufacturer's instructions, regardless of the sealing status [Fig. 1-(e)]. Each MODB onlay (a combination of six conditions in total: three CAD/CAM block types, with or without sealing) was designed and fabricated using the scanning data from the original crown form that had been obtained before the cavity preparation, using the bio-generic copy function of CEREC MCXL (4 specimens each) [Fig. 1-(f)].

Prior to the luting of the fabricated onlays to the individual cavities, the inner surface of the $\mathrm{L}$ and $\mathrm{E}$ onlays was mechanically cleaned for $10 \mathrm{~s}$ at the distance 

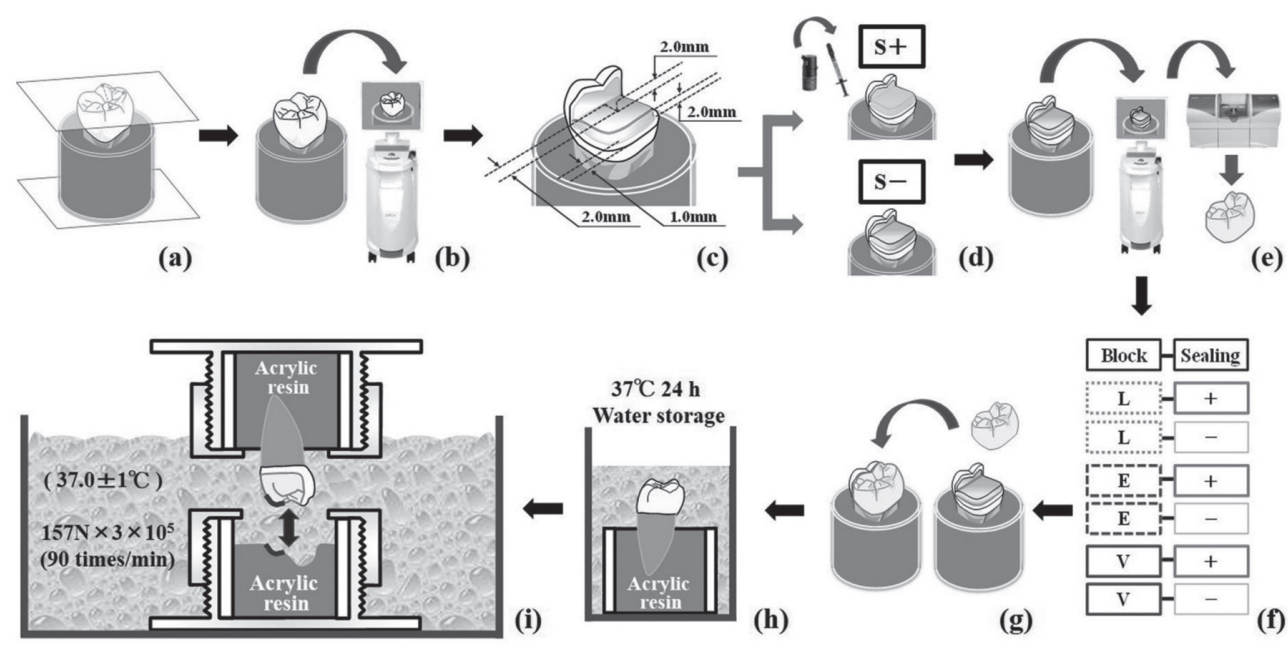

e)
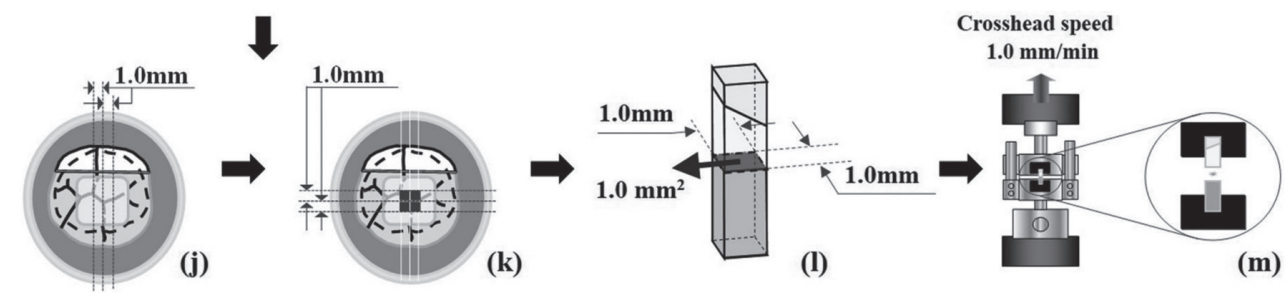

Fig. 1 Schematic flow chart of the experimental procedure.

(a) Each extracted human mandibular molar was embedded in standardized resin mold by establishing a plane on which the apexes of the buccomesial cusp, buccodistal cusp, and mesiolingual cusp were placed parallel to the base plane of the mold with an acrylic resin. (b) An optical impression was taken in order to reproduce the none-prepared original crown form for milled onlay. (c) Standardized mesial-distal-occlusal-buccal (MODB) cavities were prepared by a cavity duplicator. (d) The intra-cavity dentin surface of one-half of the cavity specimens was immediately sealed with Scotchbond Universal Adhesive and Filtek Supreme Ultra Flowable Restorative (3M ESPE, Seefeld, Germany) (e) All cavity specimens were scanned by CEREC AC Omnicam in accordance with the manufacturer's instructions, regardless of the type of sealing mode, and the MODB onlay was designed and fabricated. (f) Every MODB onlay, with the total combination of six conditions by $\mathrm{CAD} / \mathrm{CAM}$ block and sealing mode, was designed and fabricated with the bio-generic copy function of CEREC MCXL. (g) The milled onlay was cemented with Scotchbond Universal Adhesive and RelyX Ultimate to individual cavity following suitable pretreatments to both the intra-surfaces of onlay and cavity. (h) All restored specimens were stored in $37^{\circ} \mathrm{C}$ water for $24 \mathrm{~h}$. (i) The specimens were subjected to cyclic load stress. ( $\mathrm{j}$ and $\mathrm{k}$ ) Each restored specimen was sectioned intermittently and vertically. (l) Four standardized beam-shaped test pieces were trimmed and obtained from each restored specimen. $(\mathrm{m})$ The microtensile bond strength was measured at 1.0 $\mathrm{mm} / \mathrm{min}$ crosshead speed.

of $10 \mathrm{~cm}$, with $40-\mu \mathrm{m}$ aluminum oxide particles at 0.15 MPa air pressure by a sandblaster (HI-BLASTER II, Shofu). The inner surfaces of sandblasted E onlays and non-sandblasted V restorations were chemically cleaned with Scotchbond Universal Etchant. The sandblasted inner surface of $\mathrm{L}$ onlays was not chemically cleaned with etchant, in accordance with the manufacturer's instructions. Scotchbond Universal Adhesive was then applied to all inner surfaces of the three types of onlays. The intra-cavity surface of the $\mathrm{S}$ - group was pretreated with Scotchbond Universal Adhesive, and then light- cured. The intra-cavity surface of the S+ group, which consisted of enamel wall and resin-sealed dentin wall, was etched in the enamel region and the sealed dentin portion was concurrently chemically cleaned with Scotchbond Universal Etchant; Scotchbond Universal Adhesive was applied to the surface and then lightcured. Soon after, RelyX Ultimate was applied to the inner surface of each onlay, and the restoration was inserted into the relevant cavity under a constant seating force of $1 \mathrm{~kg}$ for $1 \mathrm{~m}$. Slightly hardened excess cement was carefully removed, and then light-cured from the 
occlusal, buccal, lingual, mesial, and distal directions for $20 \mathrm{~s}$ each, using the Optilux 501 [Fig. 1-(g)]. After light irradiation, the restored specimens were finished with a flame-type diamond bur (DP-05, Kuraray Noritake Dental, Tokyo, Japan) and polished with a flame-type silicone point (1F, J Morita, Tokyo, Japan) according to the manufacturer's instructions, and then stored in $37^{\circ} \mathrm{C}$ water for $24 \mathrm{~h}$ [Fig. 1-(h)].

\section{Cyclic loading and $\mu$-TBS testing}

For each restored specimen, to prepare an opposing object used for cyclic loading against the inner and the outer inclined surfaces of the occlusal cusps of the fabricated CAD/CAM onlay, a negative-impressed object was made using an acrylic resin (Adfa, Shofu) using a custom-made reproduction device establishing the 3D-positioning of an apparatus for cyclic loading. The negative-impression resin object was trimmed into the opposing object created by the inner and the outer inclined surfaces of the partially remaining occlusal cusp. All specimens were subjected to cyclic loading stress with the opposing object at $157 \mathrm{~N}$ for 90 cycles/ min for $3 \times 10^{5}$ cycles in total, in $37^{\circ} \mathrm{C}$ water, administered by a custom-made multiple-function apparatus (Tokyo Giken) [Fig. 1-(i)]. The stressed specimens were sectioned perpendicular to the cavity floor using a water-cooled microtome (Leitz 1600 Saw Microtome, Ernst Leitz, Wetzlar, Germany) [Fig. 1-(j)]. Four standardized beamshaped test pieces were obtained from the part close to the central pit of each restored specimen [Fig. 1-(k)]. The $\mu$-TBS of each test piece (cross-sectional area: $1.0 \times 1.0$ $\mathrm{mm}$ ) [Fig. 1-(1)] was measured at a crosshead speed of 1.0 $\mathrm{mm} / \mathrm{min}$ with a universal testing machine (Autograph AG-1, Shimadzu, Kyoto, Japan) [Fig. 1-(m)].

\section{Statistical analysis}

Prior to the examination of the differences in the $\mu$-TBS data $(n=16)$ between restorations with and without IDS, an F-test was performed to confirm the normal distribution. On the other hand, Bartlett's test was applied to examine the normality of the data distribution among three CAD/CAM blocks. To examine the difference in the sealing mode, the $\mu$-TBS data were statistically analyzed with an unpaired Student's $t$-test. To investigate the difference among three types of CAD/CAM blocks, the Kruskal-Wallis test, followed by multiple comparison testing, was performed using the Statistical Package for Social Sciences software (SPSS v. 16.0, SPSS, Chicago, IL, USA), with the level of significance set at 0.05 or $<0.05$ with the Bonferroni adjustment. The Steel-Dwass test was performed using JMP11 software (SAS, Tokyo, Japan) with the level of significance set at 0.05 or $<0.05$. To estimate bond reliability, the Weibull modulus and the Weibull stress value for 10 and $90 \%$ probability of failure level (PF10 and PF90, respectively), based on the $\mu$-TBS data, were determined using Excel 2010 for Windows (Microsoft, Redmond, WA, USA). The regression equation $(y=a x+b)$ for each block restoration, with and without IDS, between the probability of failure and the $\mu$-TBS, was calculated by analysis of variance for simple regression.

\section{Microscopic observation of mode of failure}

After $\mu$-TBS measurements, the mode of failure of all beam-shaped test pieces was observed under a light microscope (Measurescope MM-1200, Nikon, Tokyo, Japan) at a magnification of $\times 200$. In addition, the typical dentin-side surfaces of debonded test pieces obtained after the light-microscope observation were observed under a scanning electron microscope (S-4000, Hitachi, Tokyo, Japan) at $\times 50$ and $\times 500$ magnification, and an accelerating voltage of $5.0 \mathrm{kV}$, to confirm the components of the fracture mode.

\section{RESULTS}

Microtensile bond strength

The $\mu$-TBS test results are shown in Table 2. No pretesting failure, or debonding during trimming prior to the $\mu$-TBS testing, was observed in any of the specimens. Figure 2 shows the results of the unpaired Student's $t$-test used to examine the difference in the

Table 2 Microtensile bond strength test results

\begin{tabular}{|c|c|c|c|c|c|c|c|c|c|c|}
\hline \multirow{2}{*}{$\begin{array}{l}\text { Sealing mode } \\
\text { Restoration }\end{array}$} & \multicolumn{5}{|c|}{$\mathrm{S}-$} & \multicolumn{5}{|c|}{$\mathrm{S}+$} \\
\hline & Mean (SD) & Median & Max/Min & Q1 & Q3 & Mean (SD) & Median & Max/Min & Q1 & Q3 \\
\hline $\mathrm{L}$ & $21.2(6.1)^{\mathrm{a}}$ & $23.7^{\mathrm{A}}$ & $28.5 / 11.0$ & 14.8 & 25.9 & $26.6(6.5)^{\mathrm{b}}$ & $29.2^{\mathrm{A}}$ & $31.8 / 11.8$ & 25.7 & 30.5 \\
\hline $\mathrm{E}$ & $15.2(3.3)^{\mathrm{a}}$ & $15.5^{\mathrm{A}}$ & $19.1 / 7.9$ & 13.2 & 18.2 & $15.5(2.2)^{\mathrm{a}}$ & $15.5^{\mathrm{B}}$ & $19.6 / 12.8$ & 13.4 & 16.8 \\
\hline $\mathrm{V}$ & $3.5(1.6)^{\mathrm{a}}$ & $3.9^{\mathrm{B}}$ & $6.5 / 1.3$ & 1.9 & 4.7 & $5.1(1.2)^{b}$ & $5.0^{\mathrm{C}}$ & $7.2 / 3.3$ & 4.1 & 5.9 \\
\hline
\end{tabular}

Values in MPa with different letters indicate a statistically significant difference $(p<0.05)$.

Lowercase letters=rows, difference between two restorations with and without IDS; Uppercase letters=column, difference among L, E, and V restorations.

L, Lava Ultimate (3M ESPE, St.Paul, MN, USA); E, VITA ENAMIC (VITA Zahnfabrik, Bad Säckingen, Germany); V, VITABLOCS Mark II (VITA Zahnfabrik, Bad Säckingen, Germany); Q1, first quartile; Q3, third quartile; S-, the specimen was not sealed; $\mathrm{S}+$, the specimen was sealed immediately. 


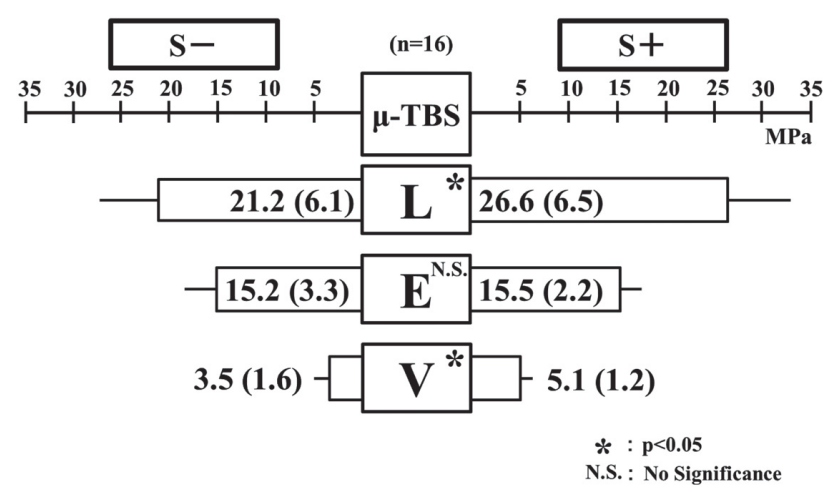

Fig. 2 Microtensile bond strength test results. $\mu$-TBS, microtensile bond strength; L, Lava Ultimate (3M ESPE, St. Paul, MN, USA); E, VITA ENAMIC (VITA, Zahnfabrik, Bad Säckingen, Germany); V, VITABLOCS Mark II (VITA Zahnfabrik, Bad Säckingen, Germany); S- the specimen was not sealed; $\mathrm{S}+$, the specimen was sealed immediately.

$\mu$-TBS between the $\mathrm{S}+$ and $\mathrm{S}-$ groups. The mean $\mu$-TBS values of the $\mathrm{L}$ and $\mathrm{V}$ restorations under the $\mathrm{S}+$ condition were significantly greater than these values under the S- condition. The Kruskal-Wallis test revealed that the $\mu$-TBS value was influenced by the block type, regardless of IDS. Figure 3 shows the results of the Steel-Dwass test to examine the difference in the $\mu$-TBS among three CAD/CAM block restorations. The $\mu$-TBS values of the $\mathrm{L}$ and $\mathrm{E}$ restorations were significantly greater than the value of the $\mathrm{V}$ restoration, regardless of IDS. Based on these results, the $\mathrm{CAD} / \mathrm{CAM}$ restoration with either of the popular resin composite blocks was significantly superior to the restoration with a feldspathic ceramic block in terms of intra-cavity bond strength, regardless of IDS.

\section{Bond reliability}

Table 3 and Fig. 4 present the Weibull parameters for the three types of restorations with and without IDS. The $\mathrm{Wm}$ values of $\mathrm{E}$ and $\mathrm{V}$ restorations in the $\mathrm{S}+$ group were significantly greater than those of the $\mathrm{S}-$ group. The CAD/CAM restorations with IDS had a tendency to be significantly superior in terms of bond reliability, defined as the reliability required to obtain the restoration-specific $\mu$-TBS. The Wm values of the $\mathrm{S}$ - group became statistically smaller according to block type, in the order $\mathrm{E}>\mathrm{L}>\mathrm{V}$. The $\mathrm{Wm}$ values in the $\mathrm{S}+$ group exhibited the order $\mathrm{E}>\mathrm{V}>\mathrm{L}$; the differences among the three restorations were statistically significant. Thus, the bond reliability of the E restorations exhibited significant superiority over the other restorations, regardless of IDS.

The differences in PF10 and PF90 stress values between the $\mathrm{S}+$ and $\mathrm{S}-$ groups and among the three block restorations subjected to Weibull analysis were examined. The difference was significant when the $95 \%$

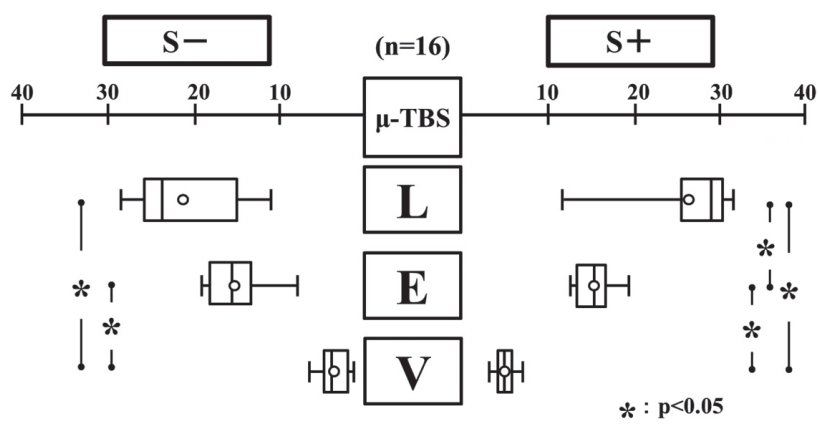

Fig. 3 Box plot of the microtensile bond strength.

The box indicates the spread of the data between the first and third quartile. The central vertical line and the circle indicate the median and the mean, respectively. Maximum and minimum values are indicated by the whiskers. $\mu$-TBS, microtensile bond strength; L, Lava Ultimate (3M ESPE, St. Paul, MN, USA); E, VITA ENAMIC (VITA, Zahnfabrik, Bad Säckingen, Germany); V, VITABLOCS Mark II (VITA Zahnfabrik, Bad Säckingen, Germany); $\mathrm{S}-$, the specimen was not sealed; $\mathrm{S}+$, the specimen was sealed immediately.

confidence intervals, the values in the parenthesis of Table 3, did not overlap ${ }^{24,25)}$. Figure 4 clearly shows that the $\mathrm{PF} 10$ values of $\mathrm{E}$ and $\mathrm{V}$ restorations in the $\mathrm{S}+$ group were significantly greater than those of the $\mathrm{S}-$ group. On the other hand, there was no significant difference in the PF90 value between $\mathrm{S}+$ and $\mathrm{S}-$ restorations, regardless of block type. From these results, in cases with low probability of failure, the $\mathrm{CAD} / \mathrm{CAM}$ restoration with IDS tended to require a significantly greater stress to debond the adhesion than restorations without IDS. Furthermore, both the PF10 and PF90 stress values of the $\mathrm{L}$ and $\mathrm{E}$ restorations were significantly greater than those of the $\mathrm{V}$ restoration, regardless of IDS, shown in Fig. 5.

\section{Distribution of modes of failure}

The distribution of the modes of failure observed under a light microscope is presented in Table 4 . No interfacial fracture was observed on any debonded surface of posttest pieces, regardless of the block type and the sealing mode. Both the mixed and the cohesive fractures were recognized in the pieces of every block restoration, regardless of the sealing mode used. In every mixed fracture, the cohesive failure was contained within the resin cement, and comprised a cohesive fracture within the adhesive layer and/or within the IDS and/or an interfacial fracture occurring at the interface between the dentin and the IDS or adhesive layer. The number of mixed fractures reduced according to block type, in the order $\mathrm{L}>\mathrm{E}>\mathrm{V}$, regardless of the sealing mode used. On the other hand, the number of cohesive fractures occurring within resin cement increased in the order $\mathrm{L}<\mathrm{E}<\mathrm{V}$, regardless of the sealing mode. 
Table 3 Weibull parameters of the three restorations

\begin{tabular}{|c|c|c|c|c|c|c|}
\hline \multirow{2}{*}{$\begin{array}{l}\text { Sealing mode } \\
\text { Restoration }\end{array}$} & \multicolumn{3}{|c|}{$\mathrm{S}^{-}$} & \multicolumn{3}{|c|}{$\mathrm{S}+$} \\
\hline & $\mathrm{Wm}$ & PF10 & PF90 & $\mathrm{Wm}$ & PF10 & PF90 \\
\hline $\mathrm{L}$ & $3.22^{\mathrm{aA}}$ & $11.9(10.1-13.3)^{\mathrm{aA}}$ & $31.0(28.1-35.5)^{\mathrm{aA}}$ & $3.24^{\mathrm{aA}}$ & $15.1(11.9-17.4)^{\mathrm{aA}}$ & $39.0(34.5-47.5)^{\mathrm{aA}}$ \\
\hline $\mathrm{E}$ & $4.60^{\mathrm{bB}}$ & $10.2(9.7-10.6)^{\mathrm{bA}}$ & $19.9(19.2-20.7)^{\text {ьв }}$ & $7.91^{\mathrm{cB}}$ & $12.4(11.5-13.0)^{\mathrm{cA}}$ & $18.2(17.5-19.3)^{\mathrm{bB}}$ \\
\hline $\mathrm{V}$ & $2.27 \mathrm{dC}$ & $1.5(1.3-1.7)^{\mathrm{dB}}$ & $5.8(5.2-6.7)^{\mathrm{fC}}$ & $4.62^{\mathrm{eC}}$ & $3.4(3.2-3.6)^{\mathrm{eB}}$ & $6.6(6.3-7.1)^{\mathrm{fC}}$ \\
\hline
\end{tabular}

Values with different letters indicate a statistically significant difference $(p<0.05)$.

Lowercase letters=rows, difference between two restorations with and without IDS; Uppercase letters $=$ column, difference among $\mathrm{L}, \mathrm{E}$, and $\mathrm{V}$ restorations.

L, Lava Ultimate (3M ESPE, St.Paul, MN, USA); E, VITA ENAMIC (VITA Zahnfabrik, Bad Säckingen, Germany); V, VITABLOCS Mark II (VITA Zahnfabrik, Bad Säckingen, Germany); Wm, Weibull modulus; PF10, the Weibull stress value in $\mathrm{MPa}$ for $10 \%$ probability of failure level (95\% confidence interval); S-, the specimen was not sealed; S+, the specimen was sealed immediately.
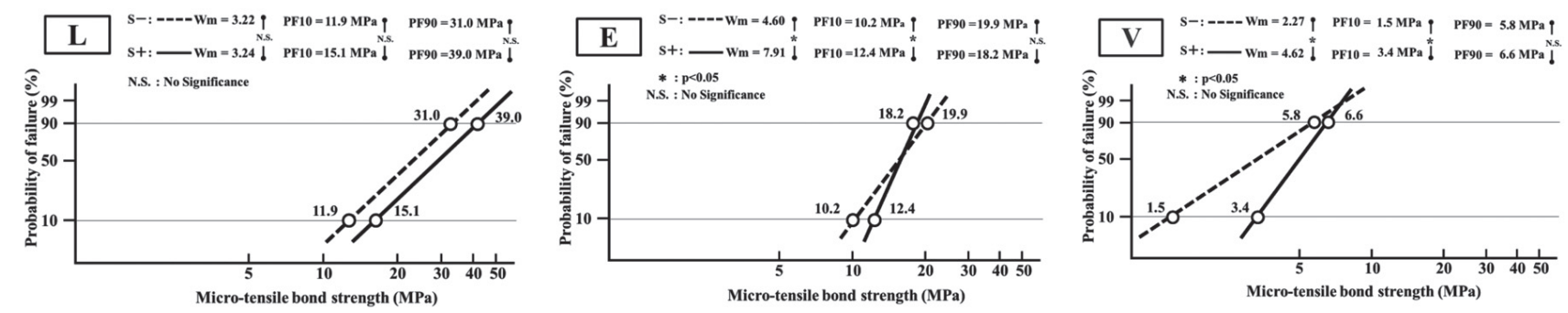

Fig. 4 Differences in the Weibull modulus (Wm) and the stress value for the 10 and 90\% probability of failure level (PF10 and PF90) between two restorations with and without immediate dentin sealing, using three types of CAD/CAM blocks.

L, Lava Ultimate (3M ESPE, St. Paul, MN, USA); E, VITA ENAMIC (VITA Zahnfabrik, Bad Säckingen, Germany); V, VITABLOCS Mark II (VITA Zahnfabrik, Bad Säckingen, Germany); Wm, Weibull modulus; PF10, stress value for $10 \%$ probability of failure level; PF90, stress value for 90\% probability of failure level; S-, the specimen was not sealed; $\mathrm{S}+$, the specimen was sealed immediately.
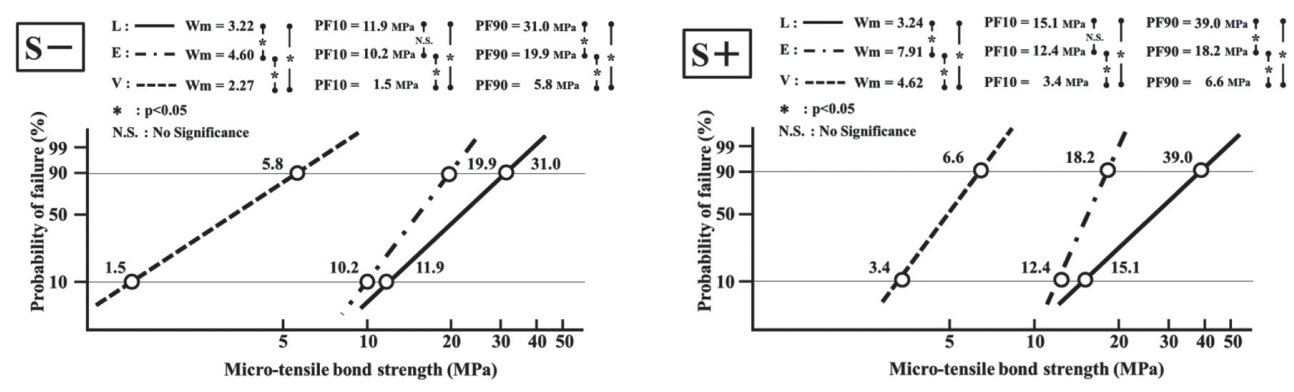

Fig. 5 Differences in the Weibull modulus (Wm) and the stress value for the 10 and 90\% probability of failure level (PF10 and PF90) among three types of CAD/CAM block restorations, with or without immediate dentin sealing.

L, Lava Ultimate (3M ESPE, St. Paul, MN, USA); E, VITA ENAMIC (VITA Zahnfabrik, Bad Säckingen, Germany); V, VITABLOCS Mark II (VITA Zahnfabrik, Bad Säckingen, Germany); Wm, Weibull modulus; PF10, stress value for $10 \%$ probability of failure level; PF90, stress value for 90\% probability of failure level; S-, the specimen was not sealed; $\mathrm{S}+$, the specimen was sealed immediately. 
Table 4 Distribution of fracture mode observed by a light-microscope

\begin{tabular}{|c|c|c|c|c|c|c|c|}
\hline \multirow{2}{*}{\multicolumn{2}{|c|}{$\begin{array}{l}\text { Restoration } \\
\text { Sealing mode }\end{array}$}} & \multicolumn{2}{|c|}{$\mathrm{L}$} & \multicolumn{2}{|c|}{$\mathrm{E}$} & \multicolumn{2}{|c|}{$\mathrm{V}$} \\
\hline & & $\mathrm{S}_{-}$ & $\mathrm{S}+$ & S- & $\mathrm{S}+$ & S- & $\mathrm{S}+$ \\
\hline \multirow{3}{*}{ Fracture mode } & Interfacial fracture & 0 & 0 & 0 & 0 & 0 & 0 \\
\hline & Mixed fracture & 13 & 15 & 11 & 11 & 4 & 4 \\
\hline & Cohesive fracture & 3 & 1 & 5 & 5 & 12 & 12 \\
\hline
\end{tabular}

Interfacial fracture: for $\mathrm{S}-$, fracture occurred at the interface between the dentin/adhesive layer; for $\mathrm{S}+$, the fracture occurred at the interface between the dentin/immediate dentin sealing material (IDS). Mixed fracture, fracture occurred within the resin cement and within the adhesive layer and/or within the IDS, and/or interfacial fracture. Cohesive fracture, fracture occurred within the resin cement.

L, Lava Ultimate (3M ESPE, St.Paul, MN, USA); E, VITA ENAMIC (VITA Zahnfabrik, Bad Säckingen, Germany); V, VITABLOCS Mark II (VITA Zahnfabrik, Bad Säckingen, Germany); S-, the specimen was not sealed; S+, the specimen was sealed immediately.

\section{DISCUSSION}

\section{Experimental conditions}

In the present study, all specimens were subjected to cyclic loading stress at $157 \mathrm{~N}$ at 90 cycles/min for $3 \times 10^{5}$ cycles in total. The force generated during routine mastication of food such as carrots or meat is approximately 70-150 $\mathrm{N}^{26)}$. Therefore, the magnitude of the load investigated in this study $(157 \mathrm{~N})$ may be similar or more severe than that experienced during normal chewing. It has been reported that the chewing rate is approximately $60-104$ cycles/ $\mathrm{min}^{27,28)}$, and the average number of chewing cycles per year is approximately $2.5-3.3 \times 10^{5}$ cycles $^{29,30)}$. In terms of cyclic loading rate and the total number of cycles, both experimental conditions in this study may have represented a loading rate similar to or greater than that experienced in normal chewing. Furthermore, based on the total number of loading cycles, it could be considered that the approximate clinical term in this study was equivalent to 1 year.

The stress of the cyclic load is one of typical intraoral environment factors. The effect of cyclic load on the $\mu$-TBS of metal-free restoration has been examined in previous studies ${ }^{14,31-34)}$, and it was clear that the $\mu$-TBS was significantly influenced by the cyclic load, and the $\mu$-TBS with a cyclic load was significantly smaller than that without a load ${ }^{31-34)}$. Therefore, a cyclic load condition was set and used for every restored specimen in this study. We used a feldspathic ceramic block, $\mathrm{V}$ which is commonly applied to CAD/CAM restorations globally and which has achieved a high success rate ${ }^{18-20)}$, as the control in this study.

\section{Influence of IDS on bond strength and reliability}

In this study, CAD/CAM restorations with IDS tended to be significantly superior in both intra-cavity bond strength and bond reliability, to the same restoration without IDS, regardless of the block type used. Thus, application of IDS may improve the bonding state of $\mathrm{CAD} / \mathrm{CAM}$ restorations, independent of the block type. Jayasooriya et al. ${ }^{15)}$ clarified that a mesial-distalocclusal cavity prepared with an adhesive system and a low viscosity microparticle-filled resin composite revealed fewer gaps at the internal dentin-restoration interface than did a non-coated cavity. Hayashi et al. ${ }^{35)}$ examined the film thickness of the cement under the same experimental condition, using a CEREC system with and without IDS. The mean cement thickness (S.D.) at the portion of the pulpal wall beneath the central pit of fabricated restoratives were 182 (26) $\mu \mathrm{m}$ for $\mathrm{S}$ - group and $134(20) \mu \mathrm{m}$ for $\mathrm{S}+$ group. There was a significant difference in the thickness between $\mathrm{S}-$ and $\mathrm{S}+$ groups at $p<0.05$. Better cavity adaptation of indirect restorations may therefore increase the intra-cavity bond strength. Islam et $a l{ }^{13)}$ indicated that using an adhesive resin coating, without a low viscosity resin composite, i.e., the same experimental condition used in the pretreatment of the restoration without dentin sealing in this study, significantly improved the $\mu$-TBS of resin cement to dentin in composite crown restoration conducted according to the conventional impression-working cast fabrication. Application of a single coating of adhesive resin to the exposed dentin surface prior to cementation should be useful for improving resin cement-dentin bond strength. The wettability and permeability of resin adhesive to both resin cement and dentin may also contribute to the bond strength. Feitosa et al. ${ }^{14)}$ mentioned that the combination of a resin adhesive system and low viscosity resin composite ensures the best bond strength of an indirect resin composite restoration after thermal and cyclic loading. However, to date, no study has examined the intra-cavity bond strength of $\mathrm{CAD} / \mathrm{CAM}$ restorations after cyclic loading with and without IDS. The results of $\mu$-TBS in this study clarified that IDS is effective not only in reinforcing the internal bond strength of $\mathrm{CAD} / \mathrm{CAM}$ restorations, but also in improving bond reliability, even after cyclic loading conditions simulating the oral environment.

Weibull analysis is particularly useful for estimating reliability ${ }^{36)}$. It is characterized by two principal parameters: the Weibull modulus, which is able to 
predict the reliability of a bond, and the Weibull stress value required to cause a failure, which can evaluate the performance of a bond at a constant percentage level (e.g., 10, 63.2, 90\% level). Robin et al. ${ }^{37)}$ reported that a high Weibull modulus is desirable for all materials, because it indicates increased homogeneity in the flaw population and a more predictable failure behavior. When data are investigated with the Weibull analysis, the ISO/TS 11405 guidelines ${ }^{38)}$ suggest that the stress values resulting in 10\% failure (PF10) and in 90\% failure (PF90) represent a convenient way to characterize the strength of a bond. It can also be considered that the Weibull stress value required to result in failure, such as PF10 or PF90, is an indicator that can be used to evaluate the performance of a bond. Tjandrawinata et al. ${ }^{39)}$ and Foster et al. ${ }^{40)}$ examined the stress that results in both PF10 and PF90 levels. However, De Munck et al. ${ }^{24)}$ mentioned that the PF10 level may be a more important property than the mean value of $\mu$-TBS, because low values may reflect early failures in clinical situations, and may be more important than high values, such as PF90 levels, which is achieved in a few cases. In this study, Weibull stress values were investigated at both PF10 and PF90 levels. Measures of both bond reliability and performance of CAD/CAM restorations with IDS tended to be significantly superior to those without IDS in cases with a low probability of failure, regardless of the block type. It could therefore be considered that restorations with IDS ensure clinical cases compared to the restoration without IDS. The manufacturerreported modulus of elasticity of the Filtek Supreme Ultra Flowable Restorative $(6.8 \mathrm{GPa})^{41)}$ and Rely X Ultimate $(7.7 \mathrm{GPa})^{42)}$ can be compared with the elasticity value of human dentin (approximately $16 \mathrm{GPa})^{43)}$. Under cyclic loading, the part of IDS that is composed of Filtek Supreme Ultra Flowable Restorative may demonstrate the greatest flexibility at the interfacial zone consisting of dentin, resin cement (Rely X Ultimate), and sealing material, thereby providing an excellent buffer effect as a stress-breaker. The presence of sealing material seems to contribute to the improvement of both bond reliability and performance.

\section{Effect of block selection on intra-cavity bond strength}

In this study, the intra-cavity bond strength was significantly greater for the two popular resin composite restorations than for a typical glass-ceramic restoration, regardless of IDS. The possible reasons for variations in bond strength with CAD/CAM block types include differences in base materials, structures, and physical and mechanical properties. The base material and structure of the CAD/CAM blocks used in this study were a hyper-cured nano-filler loaded resin ceramic (L), a honeycomb-network structured hybrid resinceramic (E), and a feldspathic fine porcelain block (V). The modulus of elasticity/flexural strength of each of these blocks have been reported by their respective manufacturers as follows: L, $12.77 \mathrm{GPa} / 204 \mathrm{MPa}^{21)}$; $\mathrm{E}$, 26-30 GPa/130-140 $\mathrm{MPa}^{22)}$; and V, 45 $\pm 0.5 \mathrm{GPa} / 154 \pm 15$ $\mathrm{MPa}^{23)}$. El Zohairy et al. ${ }^{44)}$ mentioned that higher bond strength values can be obtained with CAD/CAM composite blocks than with CAD/CAM ceramic blocks. According to the bond strength test, there is no doubt that the fracture occurs at the weakest or most damaged part of the test piece. For the L and E restorations used in this study, most (L, 81-94\%; E, 67\%) of the post-test pieces exhibited a mixed failure mode, consisting of cohesive failure in the resin cement, sealing material, and adhesive layer, and dentin-interfacial failure. For the $\mathrm{V}$ restoration, most $(75 \%)$ of the post-test pieces exhibited the cohesive failure mode in resin cement. The resin cement of the $\mathrm{V}$ restoration may be remarkably and directly damaged by cyclic loading, because of its greater modulus of elasticity compared with $\mathrm{L}$ and $\mathrm{E}$ blocks. The manufacturer-reported flexural strength/ compressive strength values of the RelyX Ultimate resin cement $\left.(98 / 262 \mathrm{MPa})^{42}\right)$ was lower than the Filtek Supreme Ultra Flowable Restorative sealing material $(121 / 318 \mathrm{MPa})^{41)}$. This may explain why the intra-cavity bond strength was significantly greater in the $\mathrm{L}$ and $\mathrm{E}$ restorations compared to the $\mathrm{V}$ restoration, regardless of IDS. It seems that the selection of a resin composite block is preferable to the feldspathic ceramic block for obtaining greater intra-cavity bond strength in the CAD/ CAM restoration.

\section{Bond reliability of $C A D / C A M$ restoration}

Ausiello et $a l .{ }^{45)}$ experimentally investigated the stressredistribution of cavities restored with indirect resin composite and glass-ceramic inlays during vertical occlusal loading by using three finite-element analyses. Their results indicated that stress distribution is best served with low modulus restorative materials and that stress redistribution occurs with the resin composite inlay. For the three CAD/CAM blocks used in this study, the modulus of elasticity was smallest for $\mathrm{L}(12.77$ $\mathrm{GPa})^{21)}$, moderate for E (26-30 GPa) ${ }^{22)}$, and largest for $\mathrm{V}(45 \mathrm{GPa} \pm 0.5)^{23)}$ restorations, which may indicate that these blocks easily transfer the cyclic loading stress to the interfacial zone of the $\mathrm{CAD} / \mathrm{CAM}$ restoration, composed of resin cement, sealing materials and resin adhesive, depending on its rigidity, in the order, $\mathrm{L}<\mathrm{E}<\mathrm{V}$. Furthermore, these three block types may possess a shock-absorbing effect in the same order.

According to the failure analysis performed in this study, most of the post-test pieces of the $\mathrm{L}$ and $\mathrm{E}$ restorations exhibited a mixed failure mode, including cohesive fracture in the resin cement (81-94\% and 67\%, respectively) and $75 \%$ of all $\mathrm{V}$ test pieces exhibited a cohesive fracture in the resin cement, with no interfacial failures. The failure analysis also indicated that the number of cohesive fractures in the resin cement increased in the order $\mathrm{L}<\mathrm{E}<\mathrm{V}$, regardless of the sealing mode. Moreover, the $\mu$-TBS and the PF10 and PF90 values of $\mathrm{L}$ and $\mathrm{E}$ restorations were significantly greater than the values of $\mathrm{V}$ restorations, regardless of the sealing mode used. It could therefore be considered that apparent and inapparent damage within the resin cement occurred with cyclic loading, and caused deterioration of bond performance in the order $\mathrm{L}<\mathrm{E}<\mathrm{V}$, 
regardless of the sealing mode. Furthermore, it seems that improvements in the physical properties of resin cement may reinforce the bonding state of CAD/CAM restorations. In this study, the $\mathrm{E}$ restoration was statistically superior to the $\mathrm{L}$ and $\mathrm{V}$ restorations in terms of bond reliability, based on the $\mathrm{Wm}$ value, and the bond performance based on PF10 and PF90 values of both the $\mathrm{L}$ and $\mathrm{E}$ restorations was significantly superior to that of the $\mathrm{V}$ restoration, regardless of IDS. The manufacturer described that $\mathrm{L}$ is not brittle and is fracture resistant, like the properties of resin composite materials for the direct restoration ${ }^{21)}$, and that $\mathrm{E}$ is the first dental hybrid ceramic with a dual network structure, with significantly lower brittleness and markedly higher elasticity than traditional dental ceramics, because the acrylate polymer network provides flexibility ${ }^{22}$. The $\mathrm{V}$ restorative was reported to be a material exhibiting very fine crystalline structures that are homogeneously embedded in the surrounding matrix, and has excellent chip-resistance, tooth-wear protection, and polishing properties ${ }^{23)}$. The bond reliability and performance of the CAD/CAM onlay restorations in this study were evaluated from the Wm and the PF10 and PF90 stress values, respectively, based on the intra-cavity bond strength data. Both the bonding properties were not influenced by the physical properties of $\mathrm{CAD} / \mathrm{CAM}$ blocks and dentin, but affected by the bonding state at the interfacial zone, because no cohesive failure within blocks or dentin was observed by the failure analysis. The bond reliability increases with the $\mathrm{Wm}$ value. Thus, the homogeneity of the flaw population at the interfacial zone (composed of resin cement, sealing material, and an adhesive layer) increases and the failure behavior becomes more predictable. The bond performance stabilizes as the stress values at PF10 and PF90 increase. Taken together, these observations indicate that the toughness increases at the interfacial zone. Bond reliability and performance of the $\mathrm{V}$ restoration may both be influenced only by the resin cement and the adhesive layer, because of the singular cohesive mode of failure. Moreover, both bond properties may have been affected by every component of the interfacial zone in the $\mathrm{L}$ and $\mathrm{E}$ restorations, where multiple modes of failure were observed.

When the bonding state was examined by Weibull analysis, the orders of the $\mathrm{Wm}$ and the PF10 or PF90 stress values did not always coincide. However, to achieve a successful clinical bonding state, it is desirable that not only the orders of the Wm and the PF10 or PF90 stress be at high position, but that the intra-cavity bond strength must also be large. Overall, it seems that the bonding state of the restorations using resin composite blocks was superior to that of restorations using a typical glass ceramic block.

\section{CONCLUSION}

Within the limitations of this study, the immediate dentin sealing (IDS) improves not only the intra-cavity bond strength, but also the bond reliability of metal-free $\mathrm{CAD} /$
CAM onlay restorations. The internal bond strength of restorations using two popular resin composite blocks (L and E) was significantly greater than that of restoration using a typical glass-ceramic block (V), regardless of IDS. Resin composite block restorations exhibited excellent bonding states, in terms of bond strength and reliability, as compared with glass-ceramic block restorations.

\section{ACKNOWLEDGMENTS}

This study was partially supported by the Japan Society for the Promotion of Science (KAKENHI Grant Number 26462899).

\section{CONFLICTS OF INTEREST}

The authors do not have any financial interest in the companies whose materials are mentioned in the article.

\section{REFERENCES}

1) Summit JB, Robbins JW, Hilton TJ, Schwartz RS, editors. Fundamentals of Operative Dentistry. A contemporary Approach. 3th ed. Chicago: Quintessence Pub; 2006. p. 293294.

2) Roberson TM, Heymann HO, Swift EJ Jr, editors. Sturdevant's Art and Science of Operative Dentistry. 5th ed. St. Louis: Mosby; 2006. p. 504-505.

3) Roberson TM, Heymann HO, Swift EJ Jr, editors. Sturdevant's Art and Science of Operative Dentistry. 5th ed. St. Louis: Mosby; 2006. p. 611-613.

4) Banerjee A, Watson TF. Pickard's Guide to Minimally Invasive Operative Dentistry. 10th ed. Oxford: Oxford University Press; 2015. p. 105-107.

5) Anadioti E, Aquilino SA, Gratton DG, Holloway JA, Dentry IL, Thomas GW, Qian F. Internal fit of pressed and computeraided design/computer-aided manufacturing ceramic crowns made from digital and conventional impressions. J Prosthet Dent 2015; 113: 304-309.

6) Fasbinder DJ. Chairside CAD/CAM: An overview of restorative. Comp Contin Educ Dent 2012; 33: 52-58.

7) Ruse ND, Sadoun MJ. Resin-composite blocks for dental CAD/CAM applications. J Dent Res 2014; 93: 1232-1234.

8) Zhi L, Bortolotto T. Comparative in vitro wear resistance of CAD/CAM composite resin and ceramic materials. J Prosthet Dent 2016; 115: 199-202.

9) Hopp CD, Land MF. Considerations for ceramic inlays in posterior teeth: a review. Clin Cosmet Investig Dent 2013; 5: 21-32.

10) Kamada K, Yoshida K, Atsuta M. Effect of ceramic surface treatments on the bond of four resin luting agents to a ceramic material. J Prosthet Dent 1998; 79: 508-513.

11) Lührs AK, Pongprueksa P, De Munck J, Geurtsen W, Van Meerbeek B. Curing mode affects bond strength of adhesively luted composite CAD/CAM restorations to dentin. Dent Mater 2014; 30: 281-291.

12) Roperto R, Akkus A, Akkus O, Lang L, Sousa-Neto MD, Teich $\mathrm{S}$, Soares Porto T. Effect of difference adhesive strategies on microtensile bond strength of computer sided design/ computer aided manufacturing blocks bonded to dentin. Dent Res J 2016; 13: 117-123.

13) Islam MR, Takada T, Weerasinghe DS, Uzzaman MA, Foxton RM, Nikaido T, Tagami J. Effect of resin coating on adhesion of composite crown restoration. Dent Mater J 2006; 25: 272 279 . 
14) Feitosa VP, Medina ADC, Puppin-Rontani RM, CorrerSobrinho L, Sinhoreti MAC. Effect of resin coat technique on bond strength of indirect restorations after thermal and cyclic load. Bull Tokyo Dent Coll 2010; 51: 111-118.

15) Jayasooriya PR, Pereira PNR, Nikaido T, Burrow MF, Tagami J. The effect of a "Resin Coating" on the interfacial adaptation of composite inlays. Oper Dent 2003; 28: 28-35.

16) Qanungo A, Aras MA, Chitre V, Mysore A, Amin B, Daswani SR. Immediate dentin sealing for indirect bonded restorations. J Prosthodont Res 2016; 60: 240-249.

17) Attita A, Abdelaziz KM, Freitag S, Kern M. Fracture load of composite resin and feldspathic all-ceramic CAD/CAM crowns. J Prosthet Dent 2006; 95: 117-123.

18) Martin N, Jedynakiewicz NM. Clinical performance of CEREC ceramic inlays: a systematic review. Dent Mater 1999; 15: 5461.

19) Posselt A, Kerschbaum T. Longevity of 2328 chairside Cerec inlays and onlays. Int J Comput Dent 2003; 6: 231-248.

20) Bindl A, Richter B, Mörmann WH. Survival of ceramic computer-aided design/manufacturing crowns bonded to preparations with reduced macroretention geometry. Int $\mathrm{J}$ Prosthodont 2004; 18: 219-224.

21) 3M ESPE. Lava ${ }^{\mathrm{TM}}$ Ultimate CAD/CAM Restorative Technical Product Profile 2016.

22) VITA. VITA ENAMIC Technical and scientific documentation 2016.

23) VITA. VITABLOCS Working Instructions 2016.

24) De Munck J, Luehrs AK, Poitevin A, Van Ende A, Van Meerbeek B. Fracture toughness versus micro-tensile bond strength testing of adhesive-dentin interfaces. Dent Mater 2013; 29: 635-644.

25) Souza EM, De Munck J, Pongprueksa P, Van Ende A, Van Meerbeek B. Correlative analysis of cement-dentin interface using an interfacial fracture toughness and micro-tensile bond strength approach. Dent Mater 2016; 32: 1575-1585.

26) Lavelle C, Relova-Quinteiro JL. Mastication: Scully C, editors. Oxford Handbook of Applied Dental Sciences. New York: Oxford University Press. Inc.; 2002. p. 149-156.

27) Neill DJ. Studies of tooth contact in complete dentures. Br Dent J 1967; 123: 369-378.

28) Shepherd RW. A further report on mandibular movement. Aust Dent J 1960; 5: 337-342.

29) DeLong R, Sakaguchi RL, Douglas WH, Pintado MR. The wear of dental amalgam in an artificial mouth: a clinical correlation. Dent Mater 1985; 1: 238-242.

30) Barkmeier WW, Latta MA, Erickson RL, Lambrechts P. Comparison of laboratory and clinical wear rates of resin composites. Quintessence Int 2004; 35: 269-274.

31) Hernandez Al, Roongruangphol T, Katsube N, Seghi PR.
Residual interface tensile strength of ceramic bonded to dentin after cyclic loading and aging. J Prosthet Dent 2008; 99: 209-217.

32) Yamada T, Maseki T, Nara Y. Effect of dynamic load on adhesion of hybrid ceramic onlay restoration. Jpn J Conserv Dent 2011; 54: 347-360.

33) Maeno M, Yamada T, Nara Y. Adhesion of CAD/CAM ceramic onlay restoration - Effect of immediate dentin sealing on intra-cavity bond strength. Jpn Adhes Dent 2014; 32: 77-87.

34) Montagner AF, Opdam NJ, Ruben JL, Cenci MS, Huysmans MC. Bonding effectiveness of composite-dentin interface after mechanical loading with a new device (Rub\&Roll). Dent Mater J 2016; 35: 855-861.

35) Hayashi K, Kawai T, Ogawa S, Maeno M, Maseki T, Dogon IL, Nara Y. Effect of optical scanner and immediate dentin sealing application on cavity adaptation of $\mathrm{CAD} / \mathrm{CAM}$ restoration. J Dent Res 2016; 95(SI-A), https://aadr2016. zerista.com/poster/member/55806. (accessed 16.07.07).

36) Weibull W. A statistical distribution function of wide applicability. J Appl Mech 1951; 18: 293-297.

37) Robin C, Scherrer SS, Wiskott HWA, de Rijk WG, Belser UC. Weibull parameters of resin composite bond strength to porcelain and noble alloy using the Rocatec system. Dent Mater 2002; 18: 389-395.

38) ISO/TS 11405: 2015. Dentistry -Testing of adhesion to tooth structure. 3rd ed, International Organization for Standardization, Geneva, 2015.

39) Tjandrawinata R, Irie M, Suzuki K. Twenty-four hour flexural and shear bond strength of flowable light-cured composites: A comparison analysis using Weibull statistics. Dent Mater J 2007; 26: 589-597.

40) Foster JA, Berzins DW, Bradley TG. Bond strength of an amorphous calcium phosphate-containing Orthodontic adhesive. Angle Orthod 2008; 78: 339-344.

41) 3M ESPE. Filtek ${ }^{\mathrm{TM}}$ Supreme Ultra Flowable Restorative technical product profile 2010.

42) 3M ESPE. RelyX ${ }^{\text {TM }}$ Ultimate Adhesive Resin Cement Technical Date Sheet 2012.

43) Chun K, Choi H, Lee J. Comparison of mechanical property and role between enamel and dentin in the human teeth. $\mathrm{J}$ Dent Biomech 2014; 5: 1-7.

44) El Zohairy AA, De Gee AJ, Mohsen MM, Feilzer AJ. Microtensile bond strength testing of luting cements to prefabricated CAD/CAM ceramic and composite blocks. Dent Mater 2003; 19: 575-583.

45) Ausiello P, Rengo S, Davidson CL, Watts DC. Stress distribution in adhesively cemented ceramic and resincomposite Class II inlay restorations: a FEA study. Dent Mater 2004; 20: 862-872. 